\title{
THE HORSE CANYON EARTHQUAKE OF AUGUST 2, 1975-TWO-STAGE STRESS-RELEASE PROCESS IN A STRIKE-SLIP EARTHQUAKE
}

\author{
By Stephen Hartzell and James N. Brune
}

\begin{abstract}
A moderate strike-slip earthquake $\left(M_{L}=4.8\right)$ occurred on the San Jacinto fault system about $60 \mathrm{~km}$ northwest of the Salton Sea on August 2, 1975. Analysis of main shock and aftershock data suggest that stress release during this earthquake took place in two stages. During one stage faulting occurred over a relatively small source area (source radius of $\sim 0.5 \mathrm{~km}$ ), with a rapid dislocaton rate (rise time $\sim 0.1 \mathrm{sec}$ ), possibly associated with an asperity on the fault. During the second stage of faulting, the rupture front grew, but at a much slower rate (rise time $\sim 10 \mathrm{sec}$ ), to a final source radius of $\sim 1.0 \mathrm{~km}$. The above model explains the larger moment estimate based on 20 -sec surface waves compared to shorter period body-wave estimates, and also the apparent increase in source dimension with time. The model allows for large stress drops over small source dimensions, but when averaged over the final extent of the rupture plane, stress drops are much lower. The rupture of the asperity is characterized by a moment of $6.5 \times 10^{22}$ dyne-cm and a stress drop of about 225 bars. The total moment is about $3.0 \times 10^{23}$ dyne-cm with an averaged stress drop over the fault plane of approximately 90 bars and a dislocation of $25 \mathrm{~cm}$. Observations similar to the ones reported on here have been noted for other earthquakes with a wide range of magnitudes, including: a few large earthquakes in Japan, the 1971 San Fernando earthquake and some of its aftershocks, the 1975 Oroville earthquake, and some swarm events in the Imperial Valley. These observations suggest that a two-stage rupture mechanism may be a fairly common occurrence in shallow faulting and may reflect possible large variations in stress over a length scale of kilometers within the crust.
\end{abstract}

\section{INTRODUCTION}

The Horse Canyon earthquake $\left(M_{L}=4.8\right)$ occurred on the San Jacinto fault system on August 2, 1975 approximately $60 \mathrm{~km}$ northwest of the Salton Sea. This earthquake is noteworthy because it was fairly well instrumented, and affords an opportunity to study the source mechanism of an earthquake in a relatively simple geological setting, predominantly hard, granitic rock. Such a location should reduce complications in the records due to scattering. Also, the Horse Canyon earthquake produced no obvious strain precursor at the Piñon Flat Geophysical Observatory (Berger and Wyatt, 1978), on the three-component laser strain meter just $13 \mathrm{~km}$ northeast of the epicenter. The mechanism of this earthquake is therefore important from an earthquake prediction standpoint.

The reported origin time is $0 \mathrm{hr} 14 \mathrm{~min} 7.5 \mathrm{sec}$, with an epicenter of $33^{\circ} 31.4^{\prime} \mathrm{N}$, $116^{\circ} 33.5^{\prime} \mathrm{W}$ and a depth of $12 \mathrm{~km}$ (Pasadena). The epicenter lies near the trifurcation of the San Jacinto fault, southeast of Anza, California (see Figure 1). The faultplane solution in Figure 1 is a lower hemisphere projection reported by Kanamori (1976). The shaded areas indicate compression. The strike and dip of the fault plane are $307.2^{\circ}$ and $71.9^{\circ}$, respectively, and of the auxiliary plane, $42.2^{\circ}$ and $75.0^{\circ}$, respectively. The solution is based on first motions from 28 Southern California stations and is fairly well constrained. Amplitudes from five stations in the Canadian network at distances greater than $20^{\circ}$, give an average body-wave magnitude of 4.3 (Basham, personal communication, 1976). Using 12-sec Rayleigh waves at eight 
Canadian stations and the procedure of Marshall and Basham (1972), an average surface-wave magnitude of 3.6 is obtained. Using the $m_{b}$ versus $M_{S}$ plot of Marshall and Basham (1972), the Horse Canyon earthquake discriminates from explosions as expected. About a dozen aftershocks in the magnitude range from 1.0 to 2.0 were recorded at Palomar (PLM) $38 \mathrm{~km}$ from the epicenter, within the first $12 \mathrm{hr}$ following the main shock.

The epicentral region is characterized by a high level of microearthquake activity,

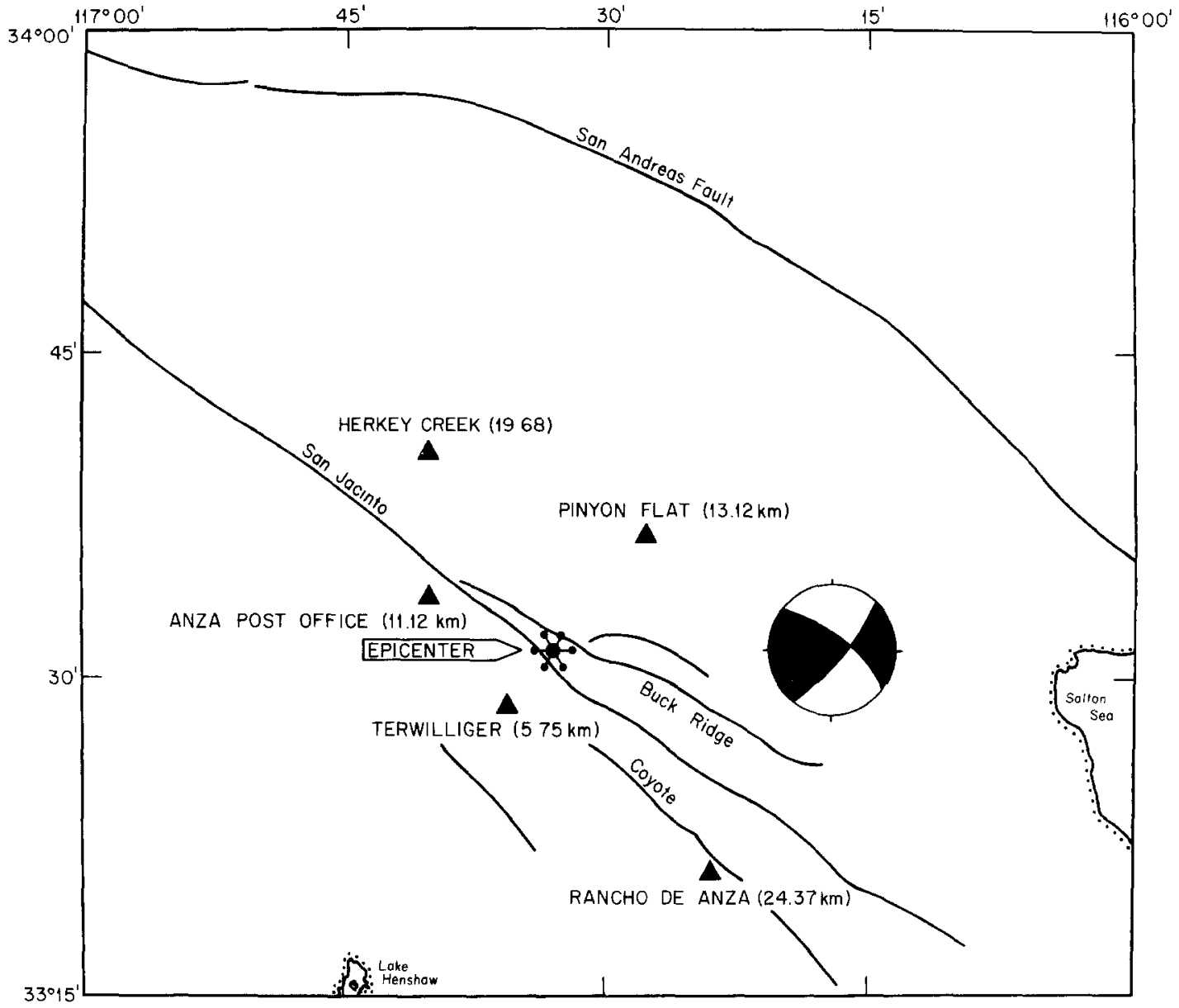

FIG. 1. Area map showing epicenter of Horse Canyon earthquake, strike-slip focal mechanism, and location of strong-motion instruments within $25 \mathrm{~km}$ of epicenter which triggered.

which occurs over a wide depth range from 3 to $15 \mathrm{~km}$ (Arabaz et al., 1970). Hypocenters of the microearthquakes do not define any simple planar surfaces, but rather are distributed over the width of the Coyote-San Jacinto-Buck Ridge fault zones (Arabasz et al., 1970). Larger historic earthquakes along the 50-km length of the San Jacinto fault around the August 2, 1975 event, include one magnitude 6.0 earthquake, the March 25, 1937 “Terwilliger Valley" earthquake (Wood, 1937), and over a dozen magnitude 4 events.

\section{Equipment and Data}

Five strong motion accelerographs (standard SMA-1) were triggered by the main shock, within $25 \mathrm{~km}$ of the epicenter. None of the aftershocks triggered the strong motion instruments. The triangles in Figure 1 indicate the accelerograph locations. 
Epicentral distances are given in parentheses. Records from these stations consist of $70-\mathrm{mm}$ film with three components of acceleration: longitudinal ( $\mathrm{N} 45^{\circ} \mathrm{W}$ ), transverse $\left(\mathrm{S} 45^{\circ} \mathrm{W}\right)$, and vertical. The vertical accelerations are small in amplitude and are not important to this study. The two horizontal components from each of the five stations were digitized at a sample interval of 0.01 sec. and corrected for the response of the instrument (Trifunac and Lee, 1973). The results are shown in Figure 2. The Pinyon Flat, Anza Post Office, and Rancho de Anza statons triggered

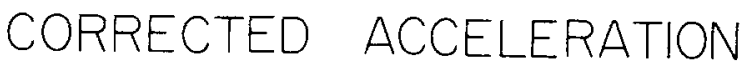

LONGITUDINAL $(N 45 W)$

TRANSVERSE (S45W)
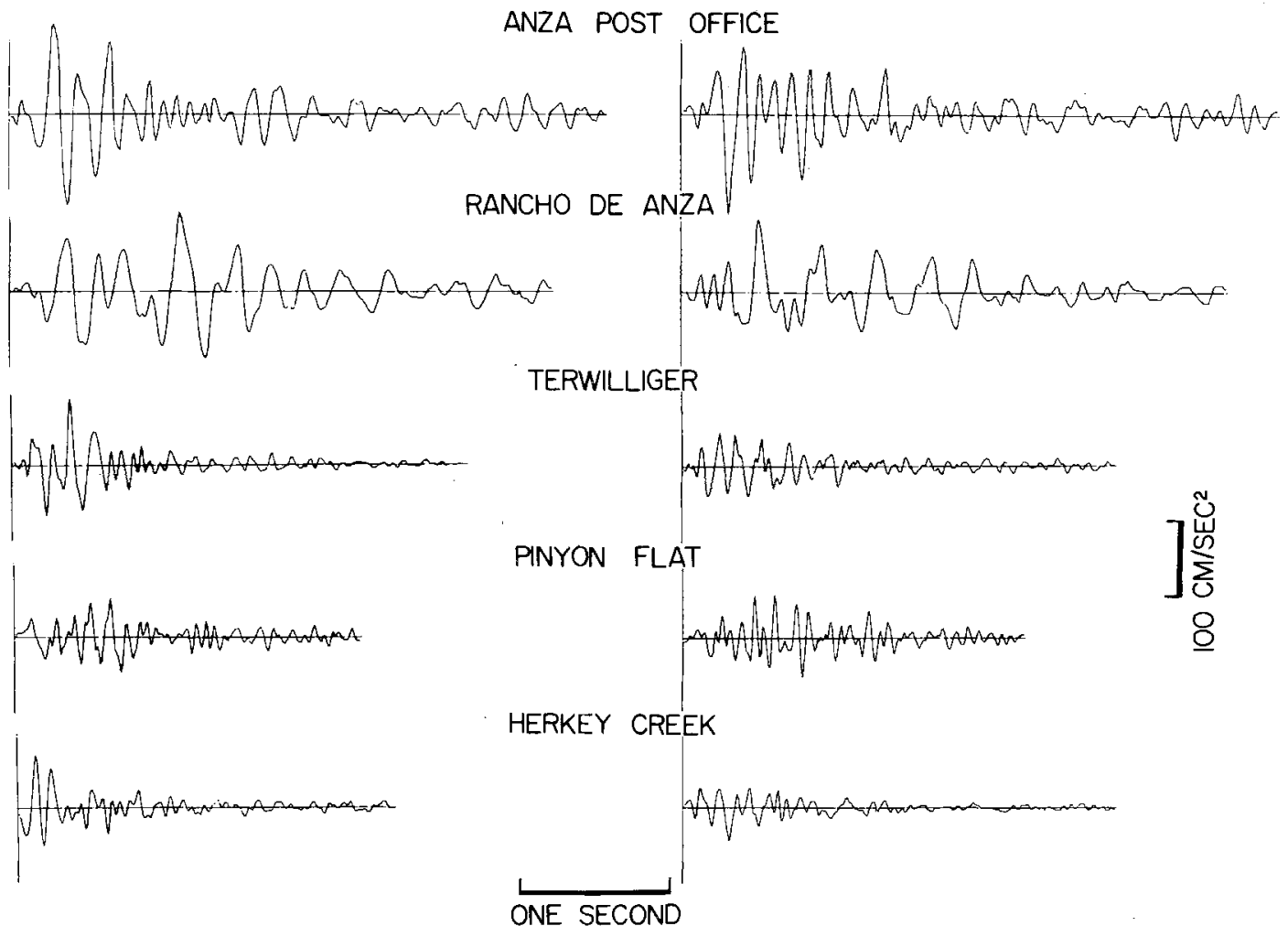

FIG. 2. Accelerograms for the strong-motion sites shown in Figure 1. All records have been corrected for the response of the instrument and start near the arrival of the $S$ wave.

on the $P$ wave, which means the first motion is lost $(\sim 0.1 \mathrm{sec})$, but the entire $S$ wave is recorded. The Terwilliger and Herkey Creek stations triggered on the $S$ wave, presumably near its onset. The largest acceleration of $130 \mathrm{~cm} / \mathrm{sec}^{2}$ occurred at the Anza Post Office station, $19 \mathrm{~km}$ from the hypocenter. The station with the next largest acceleration is Rancho de Anza, which is also the most distant of those in Figure 1. In addition, the period of maximum ground acceleration at Rancho de Anza is about a factor of two greater than the period of maximum acceleration at the other four stations. Both of the above observations are attributed to the amplification and high-frequency attenuation of the alluvium at the northwest end of the Borrego Valley, on which the Rancho de Anza station is situated.

In addition to the accelerograms for the main shock, aftershocks were recorded on a portable, digital system with a 5 -sec natural period, horizontal seismometer. 
The frequency response of the combined seismometer-recorder system is given in Figure 3 for several gain settings. The digital recorder has a sample rate of 128 samples/sec and is similar to the system described by Prothero (1976). The digital system was operated in a triggered mode with a delay line and usually recorded the first motion. Two sites were occupied; Pinyon Flat from 09:26Z to 14:48Z on August 2, and the upper end of Coyote Canyon for a period of $20 \mathrm{hr}$ starting at 19:38Z, August 2. The seismometer was aligned in a NS orientation at the Pinyon Flat site and approximately perpendicular to the trend of the Coyote Fault $\left(\mathrm{S} 45^{\circ} \mathrm{W}\right)$ at the Coyote Canyon site. The Pinyon Flat station is located about $150 \mathrm{~m}$ from the Pinyon

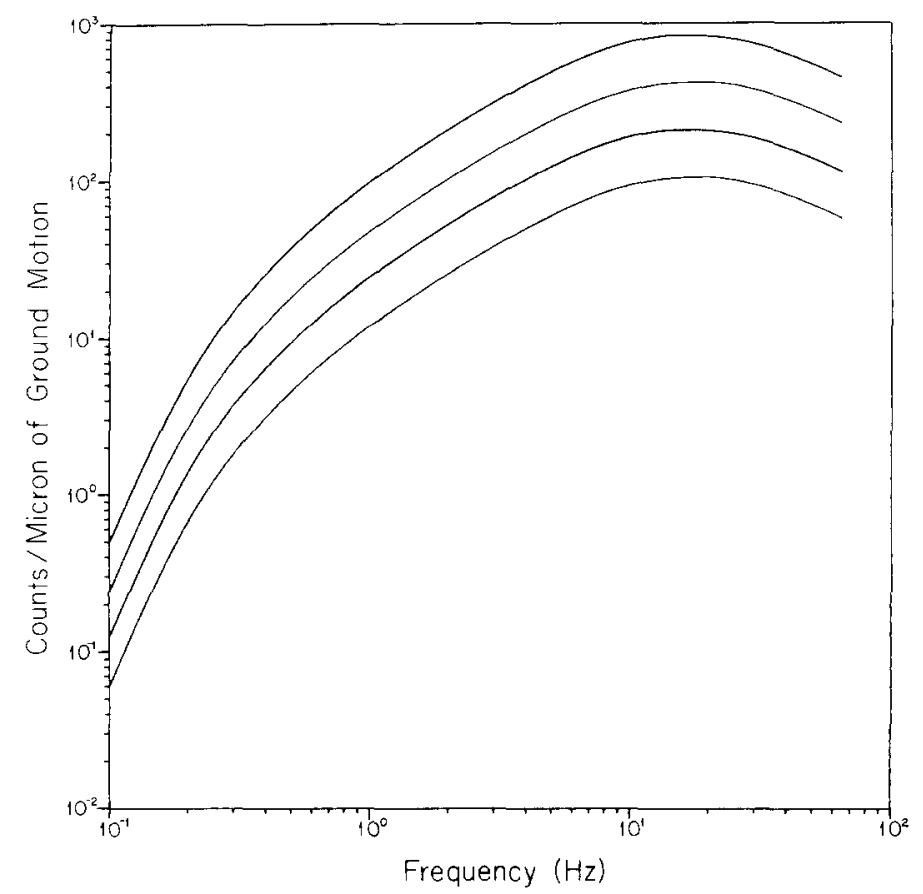

FIG. 3. Combined seismometer (period $=5 \mathrm{sec}$ ) and portable digital recorder response for four amplifier settings.

strong-motion accelerograph, which recorded the main shock. The Coyote Canyon station is $1.5 \mathrm{~km}$ NNW of the Terwilliger accelerograph.

Seven small aftershocks were recorded during the $5 \mathrm{hr}$ of operation at the Pinyon Flat site. An additional nine aftershocks were recorded at the Coyote Canyon site. A few of the aftershock records (velocities) are shown in Figure 4. Also shown for comparison are the ground velocities for the main shock, obtained from the integrated acceleration records from the Pinyon Flat and Terwilliger stations (Figure 2 ). The main shock records have been rotated into the orientation of the aftershock data. The $S$-P times of 2.2 to $2.5 \mathrm{sec}$ at Pinyon Flat are consistent with a source depth of about $12 \mathrm{~km}$, given the above epicentral location. The downward first motions at Pinyon are also consistent with the fault-plane solution of Figure 1.

\section{Surface-Wave Estimate of Moment}

The Tucson, Arizona (TUC) WWSSN long-period vertical record for the Horse Canyon earthquake has a clearly recorded Rayleigh wave (Figure 5). Surface-wave synthetics were generated using the method of Harkrider $(1964,1970)$. The faultplane solution in Figure 1 and the average continental structure KHC2 (Table 1; 

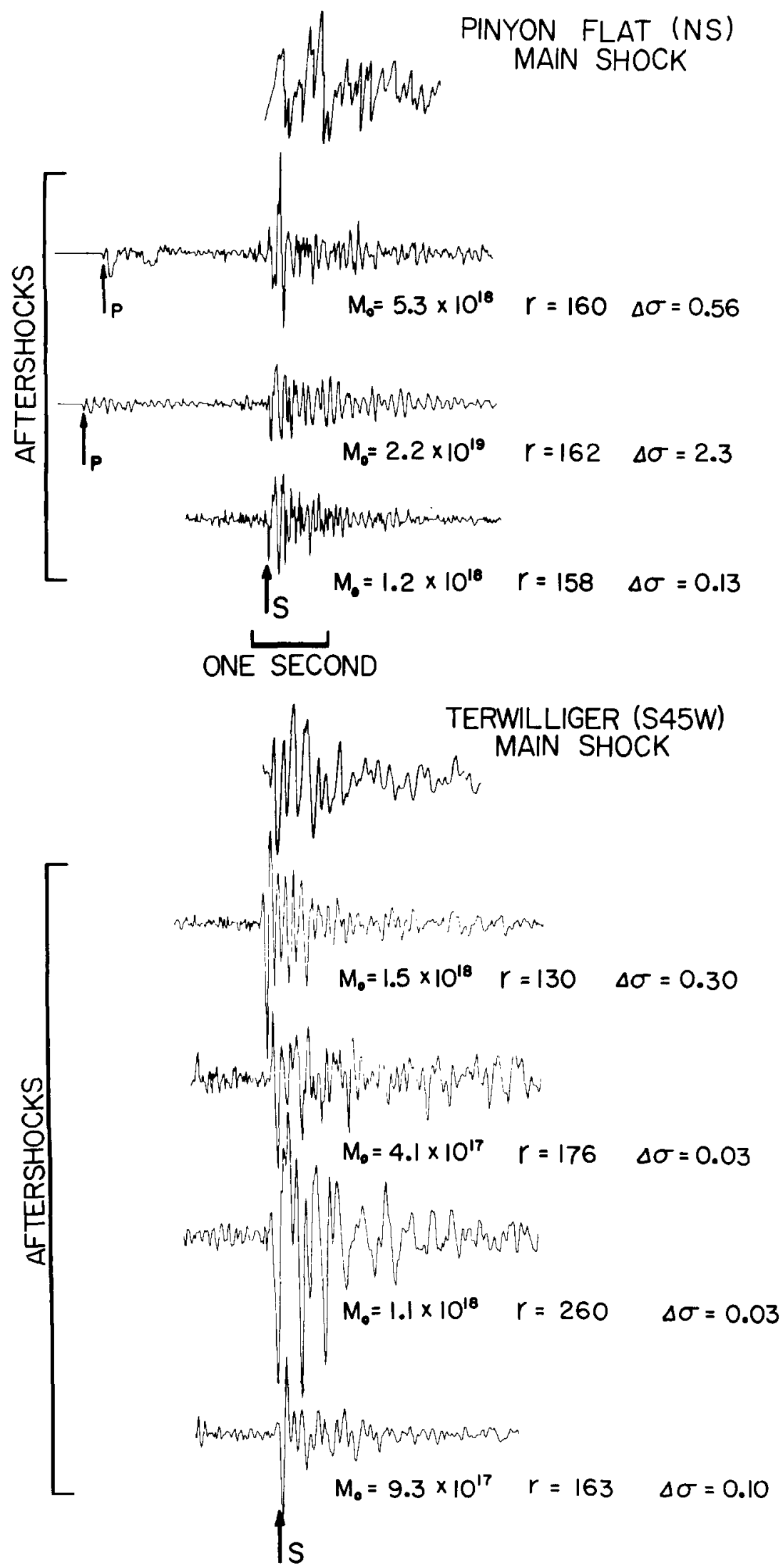

FIG. 4. Comparison of main-shock velocity records from the Pinyon Flat and Terwilliger strongmotion instruments with selected aftershock records (velocities) from the Pinyon Flat and Coyote Canyon portable digital recorder sites. 
Hiroo Kanamori, personal communication) were used. Figure 5 shows a comparison between the observed record and synthetics for a point source with a step-source time function, a source depth of $12 \mathrm{~km}$, and four different values of $Q: 50,100,200$, and 300. The leading, long-period part of the Tucson record is predominantly 20- to 30 -sec energy, whose amplitude is less sensitive to the choice of $Q$ than the shorter period energy. The long-period part of the synthetics yield moment estimates of $4.93,4.05,3.74$, and $3.34 \times 10^{23}$ dyne-cm, respectively, for the four values of $Q$. An alternative earth model was tried, model NTS-TUC from Bache et al. (1978). This

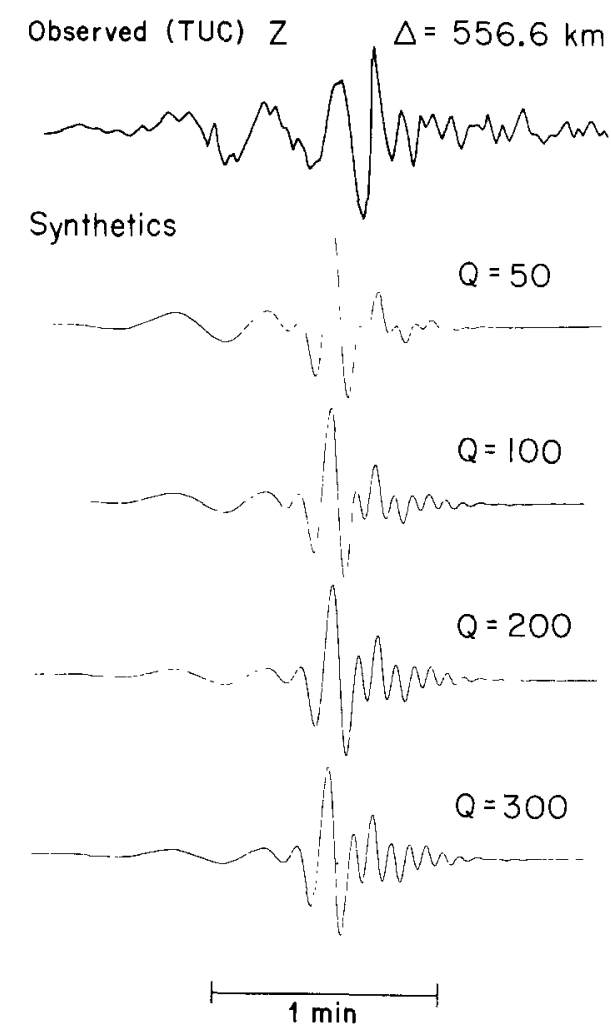

FIG. 5. TUC long-period vertical record and Rayleigh-wave synthetics for the earth structure in Table 1 and the fault-plane solution in Figure 1.

structure is based on the inversion of surface-wave data from Nevada Test Site explosions as recorded at Tucson. Model NTS-TUC gives moment estimates about 10 per cent less than model KHC2, with no better fit to the general wave form. Kanamori (1976) has also estimated the surface-wave moment of the Horse Canyon earthquake, using several different $Q$ models for the TUC and BKS records. Kanamori's values yield and average moment of about $3.0 \times 10^{23}$ dyne-cm, based on the longer period part of the records.

As a check on our calculations, the surface-wave synthetics obtained from Harkrider's program were compared with synthetics from the direct wave number integration program of Apsel and Luco (1978). Nearly identical results were obtained. The small differences are attributed to the different manner in which attenuation is handled in the two programs. 


\section{Body-Wave Estimates of Source Parameters}

Using the shear waves from the strong-motion records, the spectral theory of Brune $(1970,1971)$ may be applied to obtain body-wave estimates of source parameters. We limit the analysis to the following three components: Anza Post Office, $\mathrm{S} 45^{\circ} \mathrm{W}$; Pinyon Flat, $\mathrm{N} 45^{\circ} \mathrm{W}$; and Terwilliger, $\mathrm{N} 45^{\circ} \mathrm{W}$. These components have been chosen because their orientation is such that the records should be primarily $S H$ energy. Also, the epicentral distances are nearly the same as or less than the depth of the source, thus complications due to scattering and diffraction should be minimal. Figure 6 shows the associated displacement amplitude spectra (corrected for a $Q$ of 250) and the chosen low- and high-frequency asymptotes. Table 2 summarizes the estimates of moment $\left(M_{0}\right)$, source radius $(r)$, and stress drop $(\Delta \sigma)$, where the

TABLE 1

Model KHC2

\begin{tabular}{rrrrr}
\hline Layer & $\begin{array}{c}\text { Thickness } \\
(\mathrm{km})\end{array}$ & $\begin{array}{c}\alpha(\mathrm{km} / \\
\mathrm{sec})\end{array}$ & $\begin{array}{c}\beta(\mathrm{km} / \\
\mathrm{sec})\end{array}$ & $\begin{array}{c}\rho(\mathrm{gm} / \\
\left.\mathrm{cm}^{3}\right)\end{array}$ \\
\hline 1 & 1.0 & 2.50 & 1.44 & 2.50 \\
2 & 3.0 & 5.50 & 3.14 & 2.60 \\
3 & 23.4 & 6.30 & 3.63 & 2.70 \\
4 & 5.0 & 6.80 & 3.92 & 2.90 \\
5 & 8.6 & 8.37 & 4.73 & 3.50 \\
6 & 20.0 & 8.37 & 4.71 & 3.52 \\
7 & 20.0 & 8.08 & 4.62 & 3.47 \\
8 & 20.0 & 7.93 & 4.35 & 3.43 \\
9 & 20.0 & 7.78 & 4.18 & 3.40 \\
10 & 25.0 & 7.75 & 4.22 & 3.38 \\
11 & 25.0 & 7.78 & 4.30 & 3.36 \\
12 & 25.0 & 7.97 & 4.44 & 3.35 \\
13 & 25.0 & 8.19 & 4.56 & 3.34 \\
14 & 25.0 & 8.39 & 4.61 & 3.34 \\
15 & 25.0 & 8.52 & 4.58 & 3.37 \\
16 & 25.0 & 8.55 & 4.57 & 3.41 \\
17 & 25.0 & 8.57 & 4.57 & 3.47 \\
18 & 25.0 & 8.59 & 4.59 & 3.53 \\
19 & 25.0 & 8.64 & 4.64 & 3.59 \\
\hline
\end{tabular}

following expressions have been used (Thatcher and Hanks, 1973)

$$
M=4 \pi \mu \beta \Omega_{0} R / 0.85 ; \quad r=2.34 \beta / 2 \pi f_{c} ; \quad \Delta \sigma=(7 / 16)\left(M_{\mathrm{o}} / r^{3}\right) .
$$

We have assumed a shear-wave velocity $(\beta)$ of $3.5 \mathrm{~km} / \mathrm{sec}$ and a rigidity $(\mu)$ of 3.0 $\times 10^{11} \mathrm{dyne} / \mathrm{cm}^{2}$. The moment estimate from the Anza Post Office record is probably an overestimate, since this station is situated near the center of a small alluvial basin. The valley sediments will introduce an amplification not accounted for in the above calculation. Below we use a layered model in an attempt to obtain a better estimate. The Pinyon Flat and Terwilliger stations are located on granitic rock and should not have this problem. Because of an $S$-wave trigger, the Terwilliger record may underestimate the moment.

The displacement record, obtained by integrating the Anza Post Office accelerogram (Trifunac and Lee, 1973), was modeled with a point shear dislocation in a layered earth structure using the generalized ray method. The response of individual 


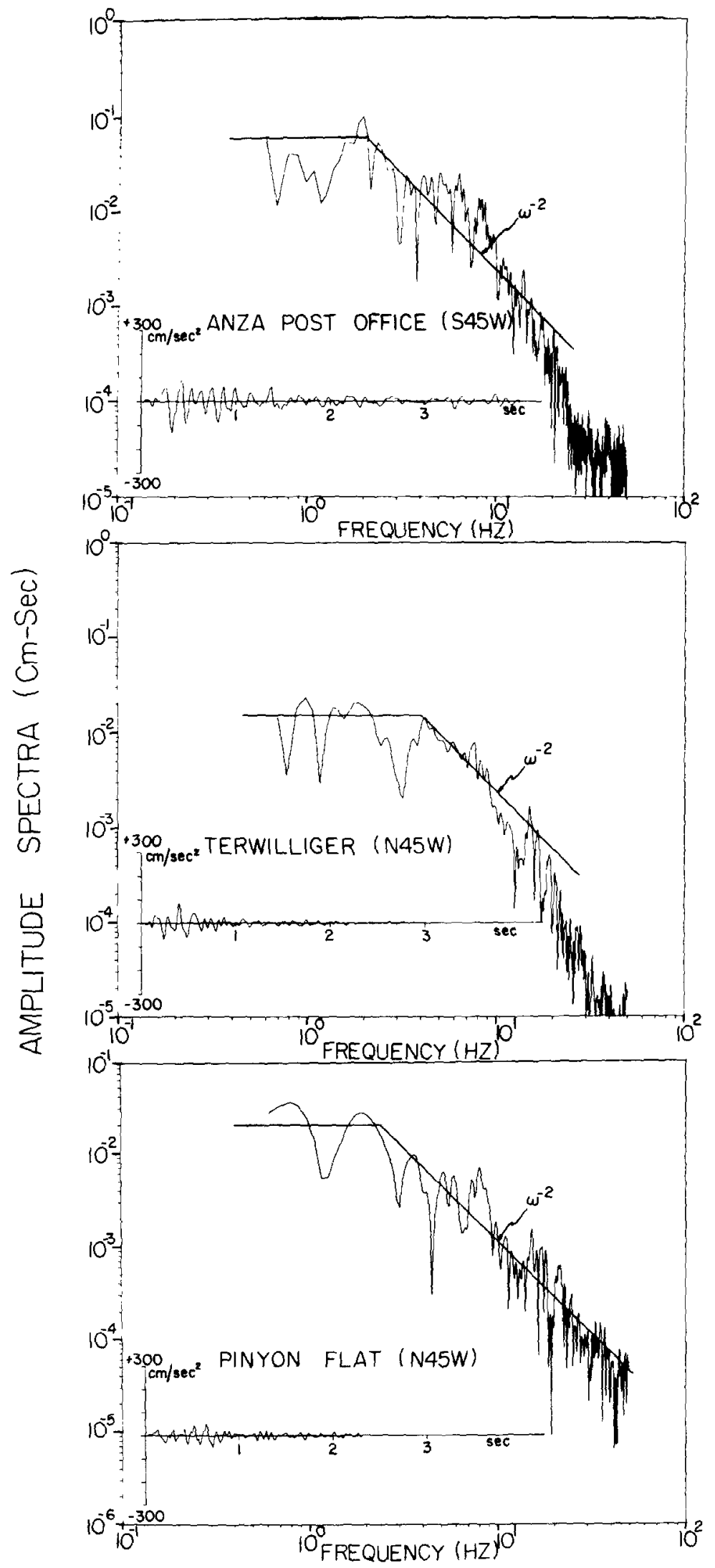

FIG. 6. Main-shock displacement amplitude spectra from the three close in strong-motion stations: Anza Post Office, Terwilliger, and Pinyon Flat. 
generalized rays is calculated by the Cagniard-de Hoop technique, and summed (Helmberger, 1974). Figure 7 compares the Anza Post Office horizontal records with the generalized ray synthetics, for the earth structure in Table 3 and the fault-plane solution in Figure 1. The earth model used here is basically a sedimentary layer over a granitic half-space. The rise time on the fault is $0.15 \mathrm{sec}$. Synthetics for a single and a double event source are shown. Both the data and the synthetics have

TABLE 2

Body-Wave Estimates of Source Parameters

\begin{tabular}{lccc}
\hline \multicolumn{1}{c}{ Component } & $\begin{array}{c}\text { Moment } \\
\text { (dyne-cm) }\end{array}$ & $\begin{array}{c}\text { Source } \\
\text { Radius }(\mathrm{m})\end{array}$ & $\begin{array}{c}\text { Stress } \\
\text { Drop (bars) }\end{array}$ \\
\hline Anza Post Office, $\mathrm{S} 45^{\circ} \mathrm{W}$ & $1.8 \times 10^{2.3}$ & 650 & 280 \\
Pinyon Flat, $\mathrm{N} 45^{\circ} \mathrm{W}$ & $6.2 \times 10^{22}$ & 590 & 130 \\
Terwilliger, $\mathrm{N} 45^{\circ} \mathrm{W}$ & $3.3 \times 10^{22}$ & 330 & 420 \\
\hline
\end{tabular}

ANZA POST OFFICE

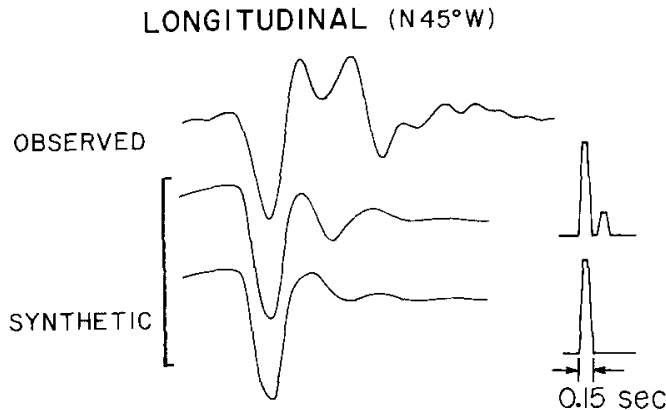

TRANSVERSE $\left(S 45^{\circ} \mathrm{W}\right)$

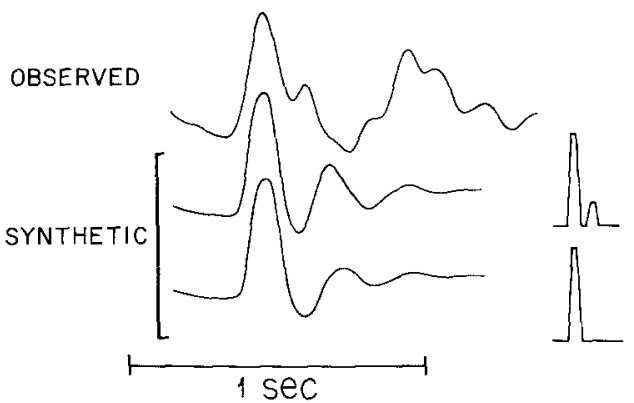

Fig. 7. Comparison of Anza Post Office main shock, horizontal displacements, and generalized ray synthetics for the structure in Table 3 and the fault-plane solution in Figure 1. The far-field source-time function is shown to the right of each synthetic.

been high-pass filtered with an Ormsby filter with roll-off frequency of $1.0 \mathrm{~Hz}$ and roll-off interval of $0.2 \mathrm{~Hz}$. In addition, the synthetics have been attenuated assuming a $Q$ of 250 . Oscillations arriving later in the data, and not explained by the synthetics, are attributed to reflections from the edges of the valley (i.e., oscillations of the sedimentary basin). The moment inferred from the above modeling is $6.6 \times 10^{22}$ dyne-cm. If we discount the Terwilliger estimate, because of an $S$-wave trigger, the preferred body-wave estimate of moment is $6.5 \times 10^{22}$ dyne-cm. In comparison, the moment obtained by averaging spectral estimates from the horizontal components for all the stations in Figure 1 is $8.0 \times 10^{22}$ dyne-cm. 


\section{Comparison of Aftershocks With Main Shock}

From the above analysis, there is about a factor of 4 to 6 discrepancy between the moment estimated from $20-\mathrm{sec}$ surface waves and body-wave estimate of moment, at a period of less than a second. This difference seems too large to ascribe to errors due to scattering, or uncertainties in the earth structure.

As stated above, the Pinyon Flat and Terwilliger accelerographs are located very close to the sites occupied by the digital system used to record aftershocks. The comparison in Figure 4 between aftershock and main-shock records points out a striking similarity. The duration and frequency content are similar, suggesting that the main shock was a simple event with a source dimension not a great deal larger than the small aftershocks. Spectral analysis of the aftershock records yields the indicated values of moment, source radius, and stress drop in Figure 4. The moment of the main shock is four to five orders of magnitude larger than the aftershock moments, yet the main-shock source radius, as inferred from body-wave analysis, is only $\sim 3$ times larger than the aftershock source radii.

The distribution of aftershocks should give a long-period estimate of the source dimension. Locations of aftershocks by Kanamori (1976) imply a source area of about $4.0 \mathrm{~km}^{2}$ (over an approximately 2 by $2 \mathrm{~km}^{2}$ area), significantly larger than the estimates in Table 2. The above data indicate larger estimates of source dimension at longer periods.

TABLE 3

Anza Post Office Structure

\begin{tabular}{cccc}
\hline Thickness $(\mathrm{km})$ & $\alpha(\mathrm{km} / \mathrm{sec})$ & $\beta(\mathrm{km} / \mathrm{sec})$ & $\rho\left(\mathrm{gm} / \mathrm{cm}^{3}\right)$ \\
\hline 0.1 & 2.50 & 1.44 & 2.50 \\
0.4 & 5.50 & 3.14 & 2.60 \\
- & 6.30 & 3.63 & 2.70 \\
\hline
\end{tabular}

\section{Discussion}

In summary, the Horse Canyon earthquake is characterized by a local body-wave estimate of moment 4 to 6 times less than the surface-wave estimate of moment. The frequency content and duration of the strong-motion records for the main shock are very similar to that of the small aftershock records. Local body-wave analysis suggests that main shock and aftershock source dimensions are not greatly different. However, the distribution of aftershocks indicate a significantly larger source dimension.

Observations similar to the ones above have been reported for other earthquakes. Kanamori (1973) attributed larger moment estimates at longer periods, for major earthquakes in Japan, to afterslip or foreslip on the fault plane with a relatively slow dislocation velocity. Tucker and Brune (1977) found two spectral corner frequencies, with an intermediate spectral slope of $\omega^{-1}$, for about half of the larger $\left(M_{L} \approx 3.5\right.$ to 4$)$ San Fernando aftershocks. This spectral shape was attributed to either afterslip or foreslip, a growing rupture in time or space, or a partial stress drop model (Brune, 1970, 1971). Similar results were obtained for a swarm of earthquakes in the Imperial Valley (Hartzell and Brune, 1977) and the August 1, 1975 Oroville earthquake (Hart et al., 1977).

In the case of the Horse Canyon earthquake, the data suggest a particular stress release process diagramatically shown in Figure 8 . Faulting initiates with a rupture over a relatively small area (source radius $\sim 0.5 \mathrm{~km}$ ) with a rapid dislocation rate (rise time $\sim 0.1 \mathrm{sec}$ ). This first phase of the rupture accounts for the simple form of 
the main shock records and the smaller body-wave estimate of source radius and moment. If the rupture from them continues to expand, but at a much slower dislocation rate (rise time $\sim 10 \mathrm{sec}$ ), most of the energy radiated will be at surfacewave periods. This phase of the rupture accounts for the larger surface-wave estimate of the moment and the larger source dimension based on the distribution of aftershocks.

In the above rupture model we have reasoned that there was an initial sharp break, followed by slip over a larger area. Actually we have not determined at what stage of the rupture process the sharp break occurred. Sliding might have first taken place over much of the $4 \mathrm{~km}^{2}$ fault surface, followed by the breaking of an asperity. However, the Pinyon Flat strain meter record suggests that faulting initiated with
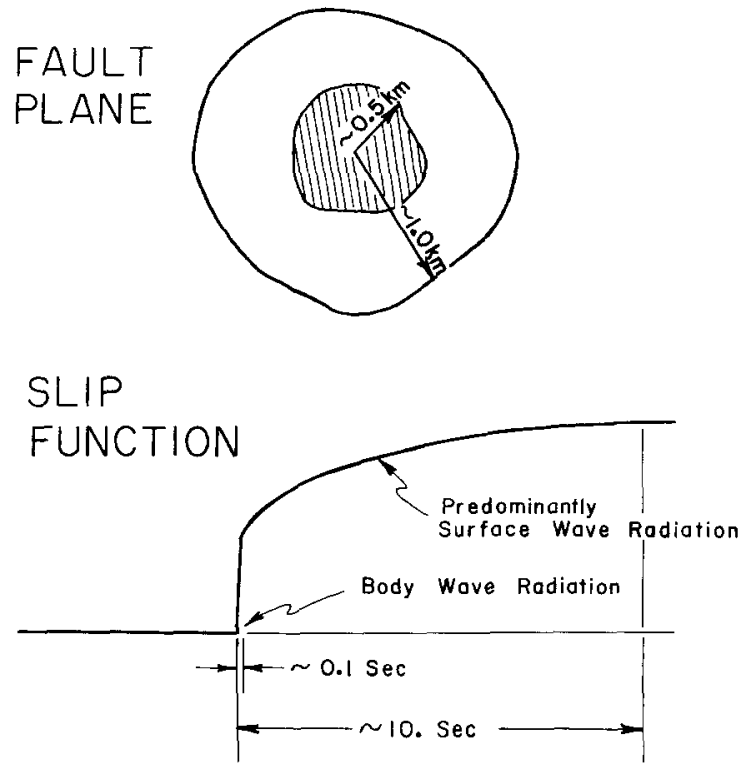

FIG. 8. Diagrammatic illustration of a possible mechanism for the Horse Canyon earthquake.

the breaking of the asperity. With a sample interval of 2 sec and an instrumental noise level of 78 counts (one fringe), all three strain components (NS, NW, and EW) show variations of less than 19 counts (1/4 fringe) for at least $60 \mathrm{sec}$ prior to the arrival of the initial earthquake phase. Only the NS component remained on scale during the earthquake. The first sample on the NS component different from the pre-earthquake level shows a jump of 12 counts. The next sample, $2 \mathrm{sec}$ later, is 917 counts above the pre-earthquake level. For an average $P$-wave velocity of $6.1 \mathrm{~km} /$ sec and the above quoted values for the hypocenter and the origin time, the calculated arrival time of the direct $P$-wave from the source is $1.5 \mathrm{sec}$ before the 12 count sample. The absolute time of the strain data is good to $\pm 0.5 \mathrm{sec}$. The origin time given above is based largely on the trigger and $S$ times at the strong-motion stations in Figure 1, making it probably a good estimate of the time of failure of the asperity. Therefore, the arrival time of the first signal on the strain record is consistent with the arrival time of the direct $P$ wave from the breaking of the asperity. If the long-period motion on the fault had taken place first, one would expect to see a clear signal about $10 \mathrm{sec}$ earlier in the strain record. Thus we conclude that this earthquake was not preceded by a long-period precursor like that suggested for some deep earthquakes (Gilbert and Dziewonski, 1975.) 
In the above model large stress drops, several hundred bars or even kilobars, may occur over relatively small source dimensions $(\leqq 1 \mathrm{~km})$, while the stress drop averaged over the final extent of the fault plane will be much less. This may be the case for the high stress drop event of 636 bars $\left(M_{L}=4.3\right)$ reported by Hartzell and Brune (1977) from the January 1975 Brawley earthquake swarm. Evidence of a similar faulting mechanism for the 1971 San Fernando earthquake is given by Hanks (1974), in which rupture begins with massive but localized failure accompanied by a high stress drop. For the Horse Canyon earthquake, a moment of $6.5 \times 10^{22}$ dyne$\mathrm{cm}$ and source radius of $0.5 \mathrm{~km}$ gives a stress drop of 225 bars for the rupture of the asperity. Continued expansion of the rupture plane increases the moment and source radius to $3.0 \times 10^{23}$ dyne-cm and $1.13 \mathrm{~km}\left(=4 \mathrm{~km}^{2}\right.$ source area), respectively, and decreases the average stress drop over the fault plane to about 90 bars. The final average dislocation is about $25 \mathrm{~cm}$.

The lack of a strain precursor at the Piñon Flat Observatory prior to the Horse Canyon earthquake may be due to the small area of the asperity. Strain could be continually relieved in the area by creep and microearthquakes, except for a few isolated asperities, which "hang up" and form points of stress concentration. An asperity will eventually break through, with a high stress drop over a small source dimension. The rupture may continue to expand outward, but subsequently will die out in the surrounding region of lower effective stress. Major earthquakes, such as the 1940 Imperial Valley earthquake (Trifunac and Brune, 1970), often appear as multiple events, which could be a cascading rupture of several such asperities.

\section{ACKNOWLEDGMENTS}

Jerry King and William Prothero assisted in the field work. The strong-motion records were supplied by the Engineering Department of the California Institute of Technology. Hiroo Kanamori kindly supplied results prior to publication. This work was supported in part by National Science Foundation Grant DES74-03188 and National Aeronautics and Space Administration Grant NGR 05-009-246, and is a contribution of Scripps Institution of Oceanography.

\section{REFERENCES}

Aspel, R. J. and J. E. Luco (1978). Dynamic Green functions for a layered half-space, UCSD Report, Department of Applied Mechanics and Engineering Science, University of California at San Diego.

Arabasz, W. J., James N. Brune, and Gladys R. Engen (1970). Locations of small earthquakes near the trifurcation of the San Jacinto fault southeast of Anza, California, Bull. Seism. Soc. Am. 60, 617-627.

Bache, T. C., W. L. Rodi, and D. G. Harkrider (1978). Crustal structure inferred from Rayleigh-wave signatures of NTS explosions, Bull Seism. Soc. Am. 68, 1399-1413.

Berger, J. and F. Wyatt (1978). Some remarks on the base length of tilt and strain measurements, in Proceedings from Conference on Measurement of Ground Strain Phenomena Related to Earthquake Prediction, Sept. 7-9, U.S. Geol. Survey Publ.

Brune, J. N. (1970). Tectonic stress and the spectra of seismic shear waves from earthquakes, J. Geophys. Res. 75, 4997-5007.

Brune, J. N. (1971). (Correction) Tectonic stress and the spectra of seismic shear waves from earthquakes, J. Geophys. Res. 76, 5002.

Gilbert, F. and A. M. Dziewonski (1975). An application of normal mode theory to the retrieval of structural parameters and source mechanisms from seismic spectra, Phil. Trans. Roy. Soc. London, Ser. A, 278, 187-269.

Hanks, T. C. (1974). The faulting mechanism of the San Fernando earthquake, J. Geophys. Res. 79, 1215-1229.

Harkrider, D. G. (1964). Surface waves in multilayered elastic media. Part I. Rayleigh and Love waves from buried sources in a multilayered elastic halfspace, Bull. Seis. Soc. Am. 54, 627-679.

Harkrider, D. G. (1970). Surface waves in multilayered elastic media. Part II. Higher mode spectra and spectral ratios from point sources in plane layered earth models, Bull. Seism. Soc. Am. 60, 19371987. 
Hart, R. S., R. Butler, and H. Kanamori (1977). Surface-wave constraints on the August 1, 1975, Oroville earthquake, Bull. Seism. Soc. Am. 67, 1-7.

Hartzell, S. H. and James N. Brune (1977). Source parameters for the January, 1975 Brawley-Imperial Valley earthquake swarm, Pageoph 115, 333-355.

Helmberger, D. V. (1974). Generalized ray theory for shear dislocations, Bull. Seism. Soc. Am. 64, 45-64.

Kanamori, H. (1973). Mode of strain release associated with major earthquakes in Japan, Ann. Rev. Earth Planet Sci. 1, 213-239.

Kanamori, H. (1976). California Institute of Technology Final Technical Report, October 1, 1975 to September 30, 1976, U.S. Geol. Surv. Contract 14-08-0001-15254.

Marshall, P. D. and P. W. Basham (1972). Discrimination between earthquakes and underground explosions employing an improved $\boldsymbol{M}_{S}$ scale, Geophys. J. 28, 431-458.

Prothero, W. A. (1976). A portable digital seismic recorder with event recording capacity, Bull. Seism. Soc. Am. 66, 979-985.

Thatcher, W. and T. C. Hanks (1973). Source parameters of southern California earthquakes, J. Geophys. Res. 78, 8547-8576.

Trifunac, M. D. and J. N. Brune (1970). Complexity of energy release during the Imperial Valley, California, earthquake of 1940, Bull. Seism. Soc. Am. 60, 137-160.

Trifunac, M. D. and V. Lee (1973). Routine computer processing of strong-motion accelerograms, Earthquake Eng. Res. Lab., Calif. Inst. of Tech., Pasadena.

Tucker, B. E. and J. N. Brune (1977). Source mechanism and $m_{b}-M_{s}$ analysis of aftershocks of the San Fernando earthquake, Geophys. J. 49, 371-426.

Wood, H. O. (1937). The Terwilliger Valley earthquake of March 25, 1937, Bull. Seism. Soc. Am. 27, 305312 .

\section{SEISMOLOGICAL LABORATORY \\ California Institute of Technology \\ Pasadena, California 91125 (S.H.H.)}

MANUSCRIPT RECEIVED SEPTEMBER 28, 1978
University of California, San Diego

Institute of GeOPhysics and Planetary Physics

SCRIPPS INSTITUTION OF OCEANOGRAPHY

La Jolla, Californta 92093 (J.N.B.) 